\title{
The puzzle of metabolic effects of obstructive sleep apnoea in children
}

\author{
Oreste Marrone ${ }^{1}$ and Maria R. Bonsignore ${ }^{1,2}$
}

Affiliations: ${ }^{1}$ Institute of Biomedicine and Molecular Immunology (IBIM), National Research Council (CNR), Palermo, Italy. ${ }^{2}$ DiBiMIS, University of Palermo, Italy.

Correspondence: Maria R. Bonsignore, c/o Ospedali Riuniti Villa Sofia-Cervello, via Trabucco 180, 90146 , Palermo, Italy.

E-mail: marisaQibim.cnr.it

@ERSpublications

In obese children with obstructive sleep apnoea insulin resistance is common while lipids do not show a clear pattern http://ow.ly/XNR9s

In adults, obstructive sleep apnoea (OSA) is often associated with metabolic alterations. Although obesity is a major culprit [1], large epidemiological studies have reported a metabolic risk associated with OSA that is independent of obesity. In particular, meta-analyses have shown that effective treatment of OSA by continuous positive airway pressure (CPAP) improves glycaemic control in both diabetic [2] and nondiabetic patients [3].

Intermittent hypoxia is an important mechanism by which OSA affects metabolism, as supported by experimental observations showing that intermittent hypoxia negatively interferes with both glucose and lipid metabolism $[4,5]$. Altered sleep structure, as often found in OSA, may also play an important role. In adult humans, experimental sleep fragmentation [6] and deprivation of slow wave sleep (SWS) [7] decreased insulin sensitivity. In healthy adolescents, two studies found that insulin sensitivity was negatively correlated to stage 1 non-rapid eye movement (non-REM) sleep, and positively to SWS duration $[8,9]$. Furthermore, in another population of healthy adolescents, partial sleep deprivation, with preserved SWS and a reduced amount of REM sleep, was followed by an increase in insulin resistance [10]. A correlation between short sleep duration and insulin resistance has also been found with actigraphic studies both in adolescents $[11,12]$ and in younger children [13].

Paediatric OSA shows major differences compared with the adult disease [14]. First, the number of respiratory events and the degree of nocturnal hypoxaemia are usually lower in children than in adults. Second, sleep duration is physiologically longer in children than in adults and respiratory events, although possibly causing some sleep fragmentation, are associated with a sleep structure that appears to be better preserved than in adults. Third, duration of disease and exposure to additional risk factors for several complications is limited in children, as opposed to the decades of exposure to sleep disordered breathing (SDB) and risk factors typical of adult patients. Therefore, differences between adults and children with OSA could explain a different impact on metabolism. The picture is even more complex if we consider that paediatric disease has two main phenotypes: one typical of lean children with adenotonsillar hypertrophy, which usually occurs at a younger age and has a similar prevalence in both sexes; and one typical of obese children that is more similar to adult OSA and usually appears in adolescence, more often in males [15]. Onset of puberty is an additional factor known to affect metabolism in children, increasing insulin resistance at least in males [16]. The impact of all these variables, and the small sample size of several paediatric studies, probably contribute to the difficulties in clear interpretation of the apparently conflicting data available in the current literature.

Received: Jan 152016 | Accepted: Jan 192016

Conflict of interest: None declared.

Copyright OERS 2016 
TABLE 1 Summary of studies on glucose and lipid metabolism in paediatric obstructive sleep apnoea (OSA) according to age and body weight

\begin{tabular}{|c|c|c|c|c|}
\hline & \multicolumn{2}{|c|}{ Insulin resistance/sensitivity } & \multicolumn{2}{|c|}{ Lipid measurements } \\
\hline & Worse in OSA & Not worse in OSA & At least one worse in OSA & Not worse in OSA \\
\hline \multicolumn{5}{|l|}{ Early childhood } \\
\hline Overweight/obese & $\begin{array}{l}\text { CAMINITI et al. [31] } \\
\text { Bhushan et al. [26] }\end{array}$ & & & \\
\hline Wide range of body weights & & $\begin{array}{l}\text { Apostolidou et al. [36] } \\
\text { KeLLy et al. [37] } \\
\text { Koren et al. [17] }\end{array}$ & & \\
\hline \multicolumn{5}{|l|}{$\begin{array}{l}\text { Adolescence } \\
\text { Normal body weight }\end{array}$} \\
\hline Wide range of body weights & REDLINE et al. [29] & $\begin{array}{l}\text { DeBoer et al. [38] } \\
\text { KeLLy et al. [37] }\end{array}$ & $\begin{array}{l}\text { Unchanged triglycerides, total } \\
\text { cholesterol and HDL, and } \\
\text { increased LDL in OSA [29] }\end{array}$ & \\
\hline $\begin{array}{l}\text { Paediatric age (3-18 years) } \\
\text { Normal body weight }\end{array}$ & & & $\begin{array}{l}\text { Unchanged triglycerides, total } \\
\text { cholesterol and LDL, and } \\
\text { decreased HDL in OSA [40] }\end{array}$ & \\
\hline Overweight/obese & $\begin{array}{c}\text { De La Eva et al. [24] } \\
\text { Lı et al. [32] }\end{array}$ & $\begin{array}{l}\text { CANAPARI et al. [20] } \\
\text { FLINT et al. [39] }\end{array}$ & $\begin{array}{l}\text { Increased triglycerides, and } \\
\text { unchanged total cholesterol, } \\
\text { HDL and LDL in OSA [20] } \\
\text { Increased triglycerides, and } \\
\text { unchanged total cholesterol } \\
\text { and HDL in OSA [39] }\end{array}$ & \\
\hline
\end{tabular}

HDL: high-density lipoprotein cholesterol; VLDL: very low-density lipoprotein cholesterol; LDL: low-density lipoprotein cholesterol.

The paper by KoRen et al. [17] in this issue of the European Respiratory Journal reports a large amount of metabolic data in over 400 children with SDB aged 5-12 years. The data indicate that both obesity and sleep fragmentation in OSA are significantly associated with altered metabolic variables, including insulin resistance and lipid profile, whereas the frequency of nocturnal respiratory events or severity of nocturnal hypoxaemia exerts a minor effect, if any. The results of this study reinforce the conclusions of studies that demonstrated a prominent role of obesity [17-21] and sleep structure [22, 23] as determinants of alterations in insulin resistance/sensitivity in children with OSA, but are at odds with other studies indicating an independent influence of OSA [24-31].

Important heterogeneity in the design of investigations, and even more heterogeneity in the populations under study, could partly account for the large disagreements in the literature. Even studies with similar populations did not always report similar conclusions, but some trends may be identified (table 1). Most studies including only obese children found a significant effect of OSA on glucose metabolism [24, 26-28, 31-32], in agreement with experimental data showing an adverse interaction of obesity and intermittent hypoxia with metabolism [33]. Studies including only non-obese subjects did not show any significant association $[19,34,35]$, but only examined preadolescent subjects. No similar studies are available in adolescents, possibly because of the low 
prevalence of OSA in lean adolescents. Studies including both obese and non-obese children with a wide age range do not convey a uniform picture [18, 21, 25, 29, 36-38]. Pubertal state, in addition to age, could exert some influence [37], although a study accounting for the Tanner stage did not support this hypothesis [39].

In addition to data on glucose metabolism, the paper by KOREN et al. [17] provides a wealth of information on lipids. Table 1 summarises the result of the available studies that reported data on lipid profiles in OSA children. Unfortunately, the picture is far from being clear. Some studies did not find any relationship between OSA and lipids $[19,28]$, while the results of other studies were discordant about which aspects of lipid metabolism may be affected by OSA, irrespective of age and obesity state of the children $[20,25,27$, $29,34,35,39,40]$.

Among the longitudinal studies, which are available only in young children undergoing adenotonsillectomy or followed without interventions, one showed an improvement in glucose and lipid metabolism at least in obese subjects after adenotonsillectomy [41], one observed an improvement in total cholesterol only [42], and one found unchanged glucose or lipid metabolism [43]. The variable degree of resolution of respiratory events during sleep and weight gain commonly occurring in lean children after adenotonsillectomy complicate this approach [14].

The study by Konen et al. [17] represents the largest published on metabolic effects of OSA in children, to date, and has to be regarded as one of the most important in this field. The focus on only one age group, i.e. young children, is another merit of this paper. To date, altogether the literature seems to suggest that in children age, obesity and, perhaps, pubertal state modulate the relationship between OSA and glucose metabolism, but the real effect of each of these factors needs to be better clarified with large studies that are homogeneous for sample characteristics. OSA severity has mostly been analysed in terms of apnoeahypopnoea index, and more rarely in terms of nocturnal hypoxaemia, although intermittent hypoxia could be an important mediator of metabolic effects $[4,5]$. Besides, the potential importance of the distribution of respiratory disorders in non-REM versus REM sleep [44] has not been addressed in children. Finally, the independent role of sleep fragmentation in the context of respiratory events during sleep should be better clarified. As regards lipid metabolism, the picture is poorly defined in both children and adults. However, some factors that could importantly influence serum lipids, like diet or physical activity, have rarely been considered and should be assessed in future studies. In conclusion, studies on the metabolic effects of OSA in children are becoming numerous [14], but the many factors at play mean the puzzle is still far from a definitive solution.

\section{References}

1 Bonsignore MR, McNicholas WT, Montserrat JM, et al. The adipose tissue in obesity and obstructive sleep apnoea. Eur Respir J 2012; 39: 746-767.

2 Feng Y, Zhang Z, Dong Z. Effects of continuous positive airway pressure therapy on glycaemic control, insulin sensitivity and body mass index in patients with obstructive sleep apnoea and type 2 diabetes: a systematic review and meta-analysis. NPJ Prim Care Respir Med 2015; 25: 15005.

3 Iftikhar I, Khan M, Das A, et al. Meta-analysis: continuous positive airway pressure improves insulin resistance in patients with sleep apnea without diabetes. Ann Am Thorac Soc 2013; 10: 115-120.

4 Louis M, Punjabi NM. Effects of acute intermittent hypoxia on glucose metabolism in awake healthy volunteers. J Appl Physiol 2009; 106: 1538-1544.

5 Drager LF, Jun JC, Polotsky VY. Metabolic consequences of intermittent hypoxia: relevance to obstructive sleep apnea. Best Pract Res Clin Endocrinol Metab 2010; 24: 843-851.

6 Stamatakis KA, Punjabi NM. Effects of sleep fragmentation on glucose metabolism in normal subjects. Chest 2010; 137: 95-101.

7 Tasali E, Leproult R, Ehrmann DA, et al. Slow-wave sleep and the risk of type 2 diabetes in humans. Proc Nat Acad Sci USA 2008; 105: 1044-1049.

8 Armitage R, Lee J, Bertram H, et al. A preliminary study of slow-wave EEG activity and insulin sensitivity in adolescents. Sleep Med 2013; 14: 257-260.

9 Zhu Y, Li AM, Au CT, et al. Association between sleep architecture and glucose tolerance in children and adolescents. J Diabetes 2015; 7: 10-15.

10 Klingenberg L, Chaput JP, Holmbäck U, et al. Acute sleep restriction reduces insulin sensitivity in adolescent boys. Sleep 2013; 36: 1085-1090.

11 Matthews KA, Dahl RE, Owens JF, et al. Sleep duration and insulin resistance in healthy black and white adolescents. Sleep 2012; 35: 1353-1358.

12 Javaheri S, Storfer-Isser A, Rosen CL, et al. Association of short and long sleep durations with insulin sensitivity in adolescents. J Pediatr 2011; 158: 617-623.

13 Spruyt K, Molfese DL, Gozal D. Sleep duration, sleep regularity, body weight, and metabolic homeostasis in school-aged children. Pediatrics 2011; 127: e345-e352.

14 Kaditis AG, Alonso Alvarez ML, Boudewyns A, et al. Obstructive sleep disordered breathing in 2- to 18-year-old children: diagnosis and management. Eur Respir J 2016; 47: 69-94.

15 Dayyat E, Kheirandish-Gozal L, Gozal D. Childhood obstructive sleep apnea: one or two distinct disease entities? Sleep Med Clin 2007; 2: 433-444.

16 Moran A, Jacobs DR Jr, Steinberger J, et al. Changes in insulin resistance and cardiovascular risk during adolescence: establishment of differential risk in males and females. Circulation 2008; 117: 2361-2368. 
17 Koren D, Gozal D, Philby MF, et al. Impact of obstructive sleep apnoea on insulin resistance in nonobese and obese children. Eur Respir J 2016; 47: 1152-1161.

18 Tauman R, O'Brien LM, Ivanenko A, et al. Obesity rather than severity of sleep-disordered breathing as the major determinant of insulin resistance and altered lipidemia in snoring children. Pediatrics 2005; 116: e66-e73.

19 Kaditis AG, Alexopoulos EI, Damani E, et al. Obstructive sleep-disordered breathing and fasting insulin levels in nonobese children. Pediatr Pulmonol 2005; 40: 515-523.

20 Canapari CA, Hoppin AG, Kinane TB, et al. Relationship between sleep apnea, fat distribution, and insulin resistance in obese children. J Clin Sleep Med 2011; 7: 268-273.

21 Shamsuzzaman A, Szczesniak RD, Fenchel MC, et al. Glucose, insulin, and insulin resistance in normal-weight, overweight and obese children with obstructive sleep apnea. Obes Res Clin Pract 2014; 8: e584-e591.

22 Koren D, Levitt Katz L, Brar P, et al. Sleep architecture and glucose and insulin homeostasis in obese adolescents. Diabetes Care 2011; 34: 2442-2447.

23 Lesser DJ, Haddad GG, Bush RA, et al. The utility of a portable recording device for screening of obstructive sleep apnea in obese adolescents. J Clin Sleep Med 2012; 8: 271-277.

24 de la Eva RC, Baur LA, Donaghue KC, et al. Metabolic correlates with obstructive sleep apnea in obese subjects. J Pediatr 2002; 140: 654-659.

25 Verhulst SL, Schrauwen N, Haentjens D, et al. Sleep-disordered breathing and the metabolic syndrome in overweight and obese children and adolescents. J Pediatr 2007; 150: 608-612.

26 Bhushan B, Maddalozzo J, Sheldon SH, et al. Metabolic alterations in children with obstructive sleep apnea. Int J Pediatr Otorhinolaryngol 2014; 78: 854-859.

27 Bhushan B, Ayub B, Loghmanee DA, et al. Metabolic alterations in adolescents with obstructive sleep apnea. Int J Pediatr Otorhinolaryngol 2015; 79: 2368-2373.

28 Hannon TS, Lee S, Chakravorty S, et al. Sleep-disordered breathing in obese adolescents is associated with visceral adiposity and markers of insulin resistance. Int J Pediatr Obes 2011; 6: 157-160.

29 Redline S, Storfer-Isser A, Rosen CL, et al. Association between metabolic syndrome and sleep-disordered breathing in adolescents. Am J Respir Crit Care Med 2007; 176: 401-408.

30 Watson SE, Li Z, Tu W, et al. Obstructive sleep apnoea in obese adolescents and cardiometabolic risk markers. Pediatr Obes 2014; 9: 471-477.

31 Caminiti C, Evangelista P, Leske V, et al. Sindrome de apnea obstructiva del sueno en ninos obesos sintomaticos: confirmacion polisomnografica y su asociacion con trastornos del metabolism hidrocarbonado [Obstructive sleep apneas in symptomatic obese children: polisomnographic confirmation and its association with disturbances in carbohydrate metabolism]. Arch Argent Pediatr 2010; 108: 226-233.

$32 \mathrm{Li} \mathrm{AM}$, Chan $\mathrm{MH}$, Chan $\mathrm{DF}$, et al. Insulin and obstructive sleep apnea in obese Chinese children Pediatr Pulmonol 2006; 41: 1175-1181.

33 Drager LF, Li J, Reinke C, et al. Intermittent hypoxia exacerbates metabolic effects of diet-induced obesity. Obesity 2011; 19: 2167-2174

34 Stefanini D, Barros E, Stefanini R, et al. Comparing the clinical profile of non obese children with sleep apnea and snoring. Braz J Otorhinolaryngol 2012; 78: 22-26.

35 Suri JC, Sen MK, Sharma R, et al. Metabolic changes in normal- and underweight children with obstructive sleep-disordered breathing. Sleep Med 2015; 16: 1366-1371.

36 Apostolidou MT, Alexopoulos EI, Damani E, et al. Absence of blood pressure, metabolic, and inflammatory marker changes after adenotonsillectomy for sleep apnea in Greek children. Pediatr Pulmonol 2008; 43: 550-560.

37 Kelly A, Dougherty S, Cucchiara A, et al. Catecholamines, adiponectin, and insulin resistance as measured by HOMA in children with obstructive sleep apnea. Sleep 2010; 33: 1185-1191.

38 Deboer MD, Mendoza JP, Liu L, et al. Increased systemic inflammation overnight correlates with insulin resistance among children evaluated for obstructive sleep apnea. Sleep Breath 2012; 16: 349-354.

39 Flint J, Kothare S, Zihlif M, et al. Association between inadequate sleep and insulin resistance in obese children. J Pediatrics 2007; 150: 364-369.

40 Alexopoulos EI, Gletsou E, Kostadima E, et al. Effects of obstructive sleep apnea severity on serum lipid levels in Greek children with snoring. Sleep Breath 2011; 15: 625-631.

41 Gozal D, Capdevila OS, Kheirandish-Gozal L. Metabolic alterations and systemic inflammation in obstructive sleep apnea among nonobese and obese prepubertal children. Am J Respir Crit Care Med 2008; 177: 1142-1149.

42 Waters KA, Sitha S, O'Brien LM, et al. Follow-up on metabolic markers in children treated for obstructive sleep apnea. Am J Respir Crit Care Med 2006; 174: 455-460.

43 Quante M, Wang R, Weng J, et al. The effect of adenotonsillectomy for childhood sleep apnea on cardiometabolic measures. Sleep 2015; 38: 1395-1403.

44 Grimaldi D, Beccuti G, Touma C, et al. Association of obstructive sleep apnea in REM sleep with reduced glycemic control in type 2 diabetes: therapeutic implications. Diabetes Care 2014; 37: 355-363. 